\title{
Learning to distinguish Insects from other arthropods with Immersive Virtual Reality
}

\author{
Aprendiendo a diferenciar los Insectos de otros Artrópodos con \\ Realidad Virtual Inmersiva \\ Víctor Garzón-Marín $^{1}$ (D), Pablo Figueroa ${ }^{1}$ (D) Jorge Molina ${ }^{1}$ \\ ${ }^{1}$ Universidad de los Andes, Bogotá D.C., Colombia \\ v.garzonm@uniandes.edu.co,pfiguero@uniandes.edu.co,jmolina@uniandes.edu.co
}

(Received: 22 October 2020; accepted: 7 May 2021; Published online: 1 June 2021)

\begin{abstract}
Insects are necessary for the prevalence of ecosystems. Insects belong to a group of animals called "Arthropods." Many people ignore how to distinguish them, thus feeling afraid of these animals because of their appearance and usually hurting them. This study explores Immersive Virtual Reality (IVR) as an educational tool focused on allowing users to deduce a rule to distinguish between insects and other arthropods. In total, 21 under graduated students participated in this study. The results indicate that students feel confident when interacting with virtual insects and manage to complete the experience, even when they were afraid of these animals. It is also evident the teacher's importance to guide in interpreting the information that is being received.
\end{abstract}

Keywords: Learning, Immersive Virtual Reality, Safe learning spaces, Insects and VR.

Resumen. Los insectos pertenecen a un grupo de animales llamados "artrópodos" y son necesarios para la prevalencia de los ecosistemas. Sin embargo, muchas personas ignoran cómo diferenciar a un insecto de otros artrópodos, sienten miedo por su apariencia, y usualmente los lastiman. Este estudio explora la Realidad Virtual Inmersiva (IVR) como una herramienta educativa enfocada en permitir a los usuarios deducir una regla para distinguir entre insectos y otros artrópodos. En este estudio participaron 21 estudiantes de pregrado. Los resultados indican que los estudiantes se sienten seguros al interactuar con insectos virtuales y logran completar la experiencia, incluso después de haber expresado miedo a estos animales. También se hace evidente la importancia que tiene el docente para orientar en la interpretación de la información que se recibe.

Palabras clave: Aprendizaje, Realidad Virtual Inmersiva, Espacios seguros de aprendizaje, Insectos y VR.

Paper type: Research paper.

\section{Introduction}

Insects play a paramount role in ecosystems; different species play different roles. Perhaps one of the most important functions that these animals perform is pollination, which consists of pollen transport among flowers, making the production of seeds and fruits possible (Campbell et al., 2019). However, the importance of insects is not limited to pollination. The degradation of many organic materials is also of vital importance. For example, Coleoptera is a species of insects that can remove the dead matter from wood, while this, in turn, becomes in their habitat and food (Miss D. \& Cuauhtémoc, 2007). Moreover, some insects degrade the feces of other animals. Insects also contribute to maintaining the balance among species since they serve as a food supply. Insects belong to a group of animals called arthropods, characterized by being invertebrates with jointed limbs, a segmented body, and an exoskeleton made of chitin (Fuller, 2020). Despite the importance of these animals, sometimes they cannot be differentiated from other arthropods and given their appearance, they can generate fears that lead them to be injured or damaged. However, there is a rule to make this distinction, insects unlike other arthropods such as spiders or centipedes, have three pairs of jointed legs and two or four wings (most adult ones) (Bethke et al., 2014). This rule, although simple, is not in the general domain.

The course entitled "Insectos y civilización" seeks to introduce students as part of their scientific thinking training to the world of insects and their interactions. This course, which is fundamental and 
multidisciplinary, includes elements of history, anthropology, economics, culture, biotechnology, and ecology. By the end of the course, students are expected to become familiar with insects and understand the important role these animals play in ecosystems' prevalence. One of the sections of the course carries out an activity seeking students to infer the previous rule. Through the exercise, students are divided into groups of 15 individuals. These groups must visit the natural history museum one by one. At the museum, they approach and evaluate dead arthropods guided by the instructor. However, some issues further complicate the exercise's success; for example, aspects such as the size of the animals make it difficult to count their legs. Additionally, since various groups evaluated these dead animals previously, they may have lost their wings or any body parts, resulting in not enough information to infer the rule. Moreover, some students finally feel afraid and decline to approach the animals and carry out the activity.

Therefore, an alternative is necessary to allow this activity's execution while avoiding the set of difficulties outlined above, finding in Virtual Reality (VR) an option for this need. This work focuses on developing a VR experience that allows students to interact with a set of arthropods. Students must observe and classify these animals and infer a general rule to differentiate an insect from other arthropods. This paper is structured as follows: Section 2 presents a review of the related work; Section 3 describes the methodology, including describing the experience and its implementation; Section 4 presents the results, Section 5 a discussion. Finally, Section 6 shows conclusions.

\section{Related work}

In order to investigate the use of technology related to VR and learning about insects, a review of related works was carried out from three thematic groups:

1. The use of virtual reality for educational purposes

2. Works that relate the use of VR with insects, not necessarily in education

3. Research work involving technology and learning about insects

A search was made in databases such as IEEE Xplore, ACM, and Springer, using the Google Scholar search engine. In the first group, it was possible to identify that in recent decades the use of virtual reality for educational purposes has become an area of research interest, with advantages such as the possibility of executing inconceivable tasks in the real world (Southgate et al., 2019); better assimilation of concepts and motivation by students to carry out educational activities (Cho \& Lim, 2017); easier retention of information and its subsequent application in the real world (Radianti et al., 2020); and the possibility of training and testing in completely safe and controlled spaces (Carruth, 2017). Likewise, examples of the application of this tuple (VR and education) found in the literature include military training (Ahir et al., 2020), architecture (Afrooz et al., 2019), medicine (Adefila et al., 2020), among others.

In the second group, works focused mainly on the treatment of phobias were found. Studies such as McCann et al. (2014) perform a review focused on VR to treat disorders between 1995 and 2012, finding that the most treated disorders in the 27 reviewed papers were arachnophobia, acrophobia, and agarphobia. Miloff et al. (2019) present an interesting approach, comparing the efficacy of a therapy to treat spider phobias using virtual reality with standard exposure therapy. The results showed that using VR reduces phobia symptoms in the short term and was non-inferior to standard exposure therapy in the long term. Other works, like Nigam et al. (2011) uses AR to identify insects using a database of images. This application seeks to help farmers to avoid damaging insects that are not dangerous to crops. In the third group, regarding the exploitation of technology as a tool for learning about insects, few works have focused on this topic. Courses in Biology of Insects could use existing resources, such as videos (Lin et al., 2018) or visiting a museum. This is a good starting point for current work. However, it is expected to have an interactive experience similar to that carried out in the museum. Maybe with videos, there is no real interaction between students and the animals, and some body parts cannot be perceivable, causing misunderstandings in the features of the insects. Finally, Tarng et al. (2015) consists of a butterfly ecosystem built with AR. Students can use their smartphones or tablet PCs to find the butterflies within the space intended for the experience and learn about their life cycle and the different growing stages. 


\section{Methodology}

This section describes the experience developed. Firstly, it presents the participants of the study. Secondly, the process of designing the activity, and thirdly, the technology used to build it.

\subsection{Students}

21 Students from multiple courses volunteered to perform this experience. Participants' ages ranged from 17 to 24 years. They all reported not having taken a biology or medicine course previously and not having used a VR helmet before. Before beginning the experience, they were informed about the devices they would use, and an explanation on how to operate the controllers was provided. They signed a consent where information about the experience was provided and information about the risks regarding the use of VR helmets.

\subsection{Experience description}

Initially, the experience was designed in three parts. The first part consisted of a tutorial where students learn about the controls and how to interact with the virtual world. In the second part, students were expected to deduce the rule to identify an insect while predefined steps led them. The third part was an environment where multiple animals walk and fly around the students while their reactions were observed. Subsequently, and to shorten the experience, it was redesigned by integrating the first and third parts. Thus, the third-part environment served as a tutorial to allow students to learn the controls. Figure 1 shows the resulting first environment.

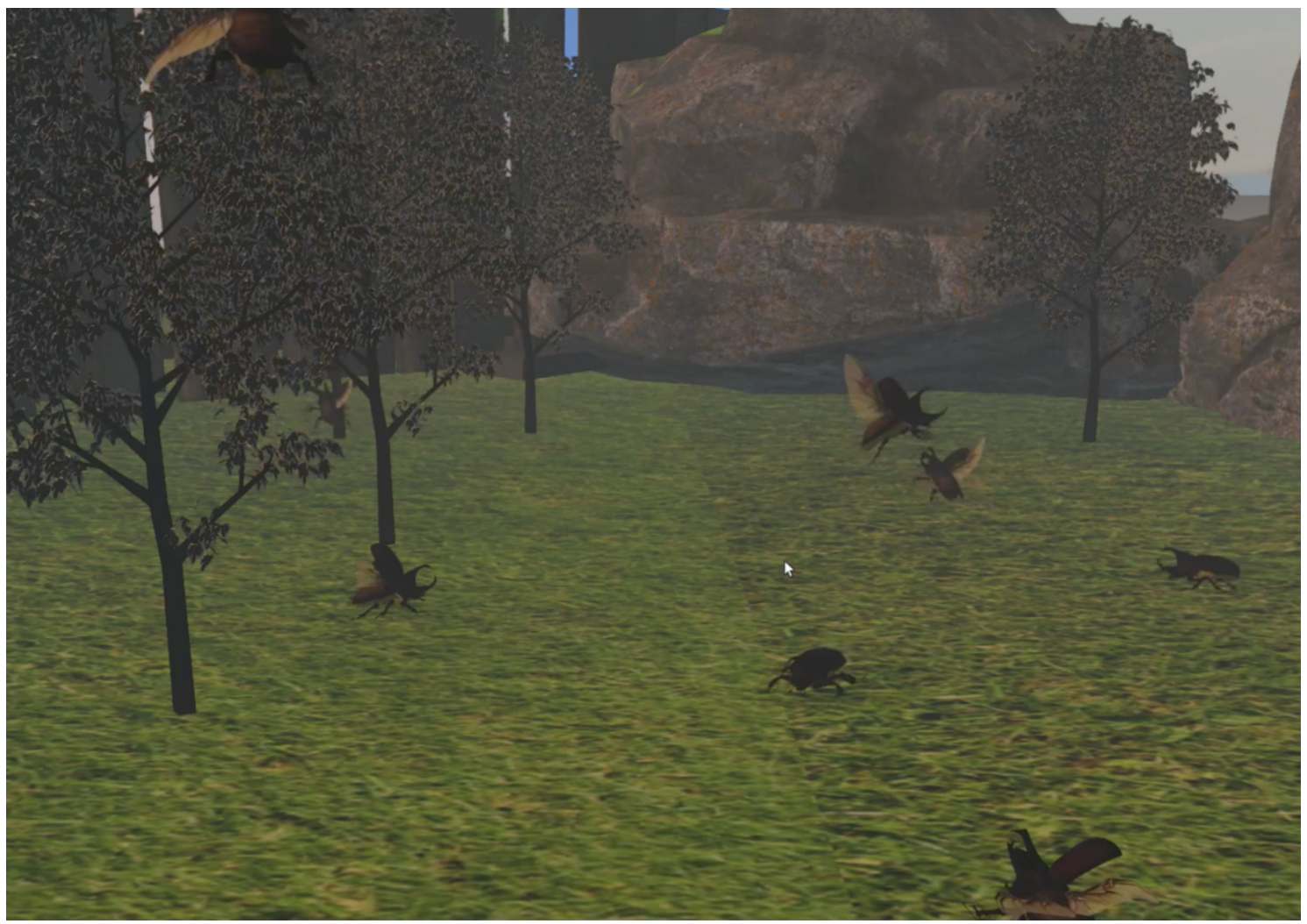

Figure 1. Screenshot. First Environment

The second part is considered the most important of the experience since its objective is to allow participants to infer the rule to distinguish an insect from other arthropods. It was designed based on the 
activity that the students of the course "Insects and Civilization" carry out in the museum. This part of the experiment is performed with a set of 6 arthropods: cockroach, spider, bee, centipede, beetle, and butterfly. The student who performs the activity must examine these animals guided by the following steps:

1. The student without prior knowledge must classify the animals into insects and not insects. To do this, there is a green box where he must locate the animals he considers insects, and a red box where he places the other ones. An observer takes notes of the decisions of the student. Figure $2 \mathrm{a}$ shows the insects which have to be classified.

2. The student must classify the animals according to the number of legs. To do this, he must take the animals, count their legs, and place them over the configurable boxes. Configurable boxes allow the student to define how many legs the animal located on it will have. Again, an observer takes note of the student's decisions. Figure $2 \mathrm{~b}$ shows a screenshot while the legs of a spider are being counted.

3. At this step, the student must classify the animals with and without wings. To do this, he must locate the winged animals over the green box and the other ones over the red box. An external observer takes notes of the student's decisions. The VR experience ends with this step. Figure 2c shows one of the animals with wings, and Figure $2 \mathrm{~d}$ shows a configurable box.

4. Once the VR experience is completed, the student must answer some questions based on his previous decisions. The most important question is proposing a rule that allows him to define what an insect is. The rule expected to be inferred is that an insect has wings and only has six legs.

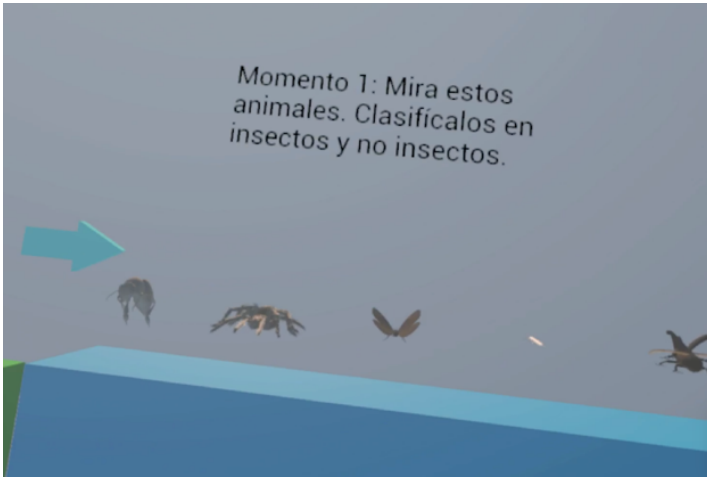

(a) Insects to be classified

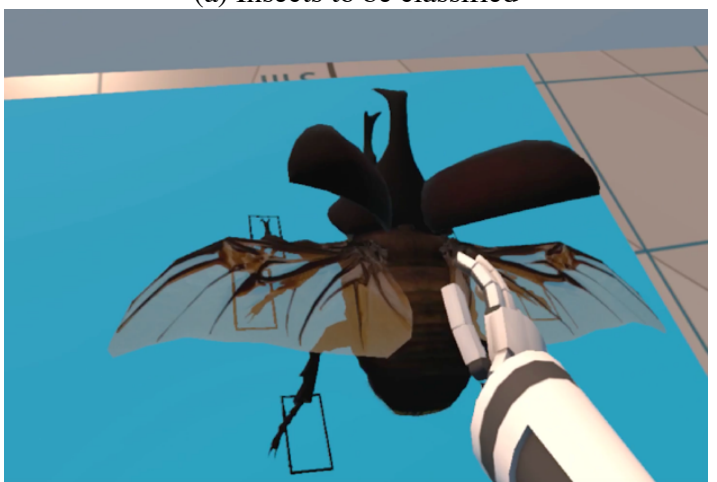

(c) Beetle

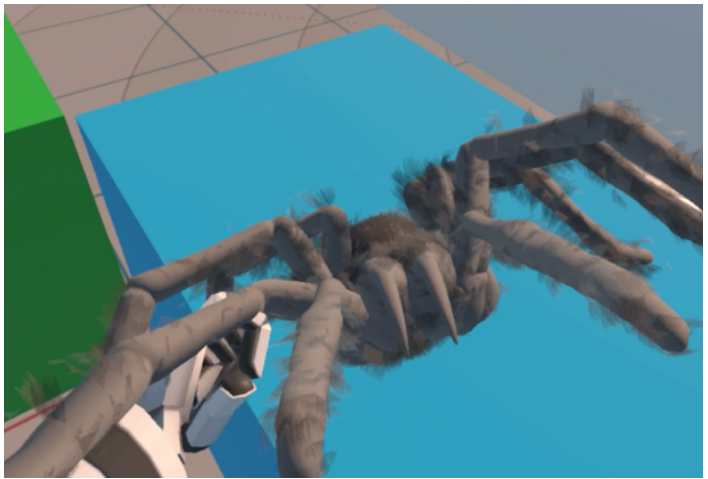

(b) Spider

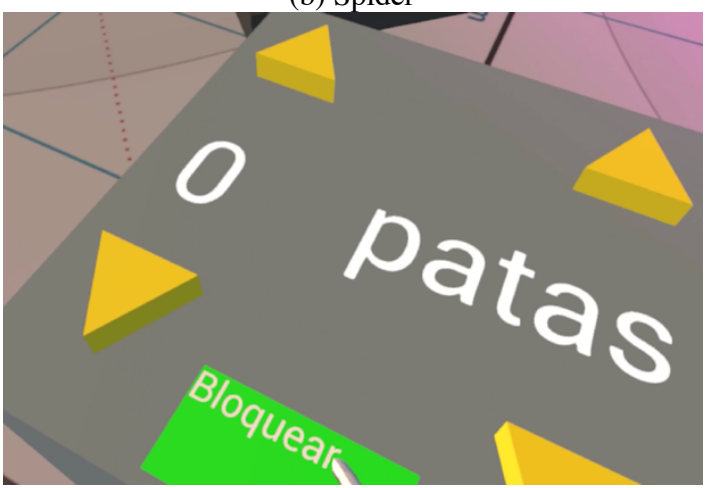

(d) Configurable Box

Figure 2. Screenshots of the second part of the experience

\subsection{Apparatus}

This experience was developed using HighFidelity (High Fidelity Inc., 2021), an open-source platform that helps construct VR environments. This platform was used because the activity is expected to be extended as a collaborative task, and HighFidelity properly allows interaction between users. Additionally, it works well as a prototyping tool. The developer does not have to worry about the controllers for the different VR helmets, the communication between users, or the handling of avatars. HighFidelity provides all this. The 
tests were executed with an Oculus Rift HMD and later with an HTC Vive PRO. The last one gave better results since the animals on the floor were easier to pick up. Thus, HTC Vive PRO was selected for testing with students. The animal models were acquired from a 3D model store. This is an online platform where 3D designers publish and sell their models. A Biologist evaluated the acquired models to identify the representation's accuracy, including the design, used textures, and their animations.

\subsection{Implementation description}

The 3D environments are like mock-ups containing multiple virtual objects. Every virtual object in HighFidelity is called an "Entity" and has a unique ID to be differentiated from other entities. HighFidelity uses a client-server architecture, and the environments are stored at the server-side, and a user needs a client application to connect to it. Multiple users can connect to an environment, interact with the entities, and communicate between them. To allow the construction of the logic or behavior associated with an environment, HighFidelity can execute JavaScript code (High Fidelity Inc., 2021). The environments developed for this experience use the 3D models acquired, some primitives models (cubes, cylinders, spheres) provided with HighFidelity, and some scripts to implement their logic. The first experience environment is the simplest one, and it executes JavaScript code at the server-side to create instances of the arthropods. Every arthropod is an entity composed by a 3D Model and a script to manage its animation, update its position inside the environment, and even destroy the instance after a certain time. Figure 3 shows a map of the second experience environment. The following elements can be highlighted in it:

- Start button: This object is presented during the whole experience, and it allows the user to navigate between each one of the steps defined in section 3.2. Once the user completes a step, he must press this button, and the environment will update the elements to start the next one. This button has a Client Entity Script associated, which is a script executed at the client-side. This script has references to all entities' IDs in the environment. Using these IDs, the script can hide and present elements such as the boxes, update the step description, and sort the animals.

- Step description: It is displayed as a screen on the wall, used to present the user's activities to complete the current step.

- Animals: The six animals that have to be classified are presented over a blue box. These animals are entities with the grabbable, so the user can touch and move them.

- Yes/no Boxes: Some steps like 1 (which one is an insect) and 3 (which one has wings) require the use of these boxes to classify the animals.

- Configurable boxes: These boxes contain a couple of buttons to set information. For example, in step 2 , the user can use the configurable boxes to group the animals by the number of legs. These boxes use a Client Entity Script to implement their interactivity. 

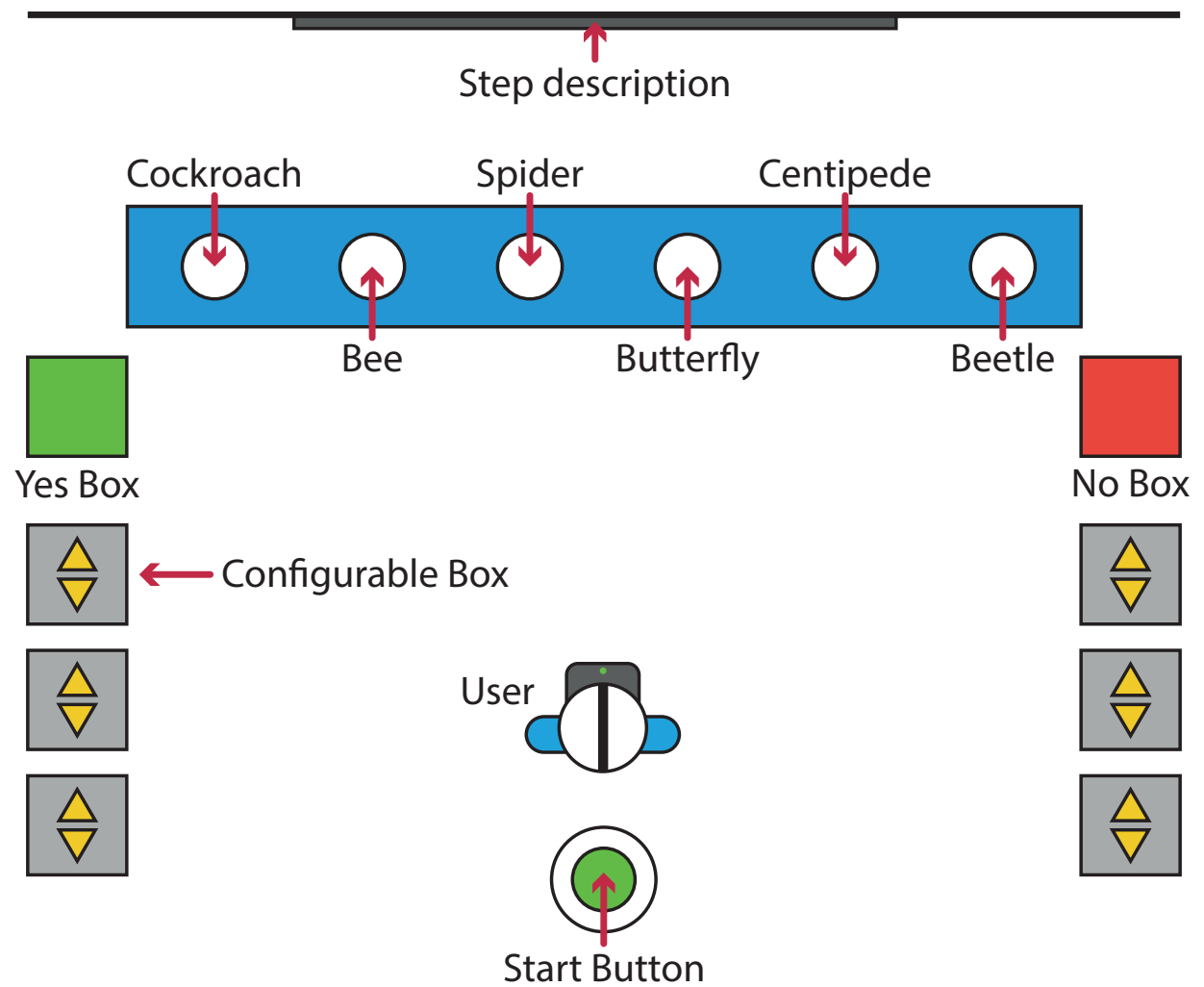

Figure 3. Map Experience Part 2

\section{Results}

The results can be divided into two parts. The first one regards the motivation that could be observed developing the experiences. Although some of the students expressed such fear of insects that their hands sweated and even released the controls, they were constantly asked if they felt good to continue with the test. In all cases, the answer was yes. However, this is an opportunity for improvement since for future versions of this type of experiment, it is necessary to have medical support in case of any eventuality. In the second part, the results are shown with respect to the classification made. Figure 4 shows the percentage of students who marked each arthropod as an insect at the beginning of the experience. The bars with vertical lines represent the animals that are insects, and the bars with horizontal lines those that are not. It is possible to observe that in the case of the bee and the beetle, $100 \%$ of students easily determined that they were insects. With others, certain doubts may appear. The clearest case of error is with the centipede, which is not an insect, but more than $70 \%$ of students marked it as one. This result shows the lack of knowledge about these animals and supports the fact of not having a clear distinction between insects and other arthropods. 


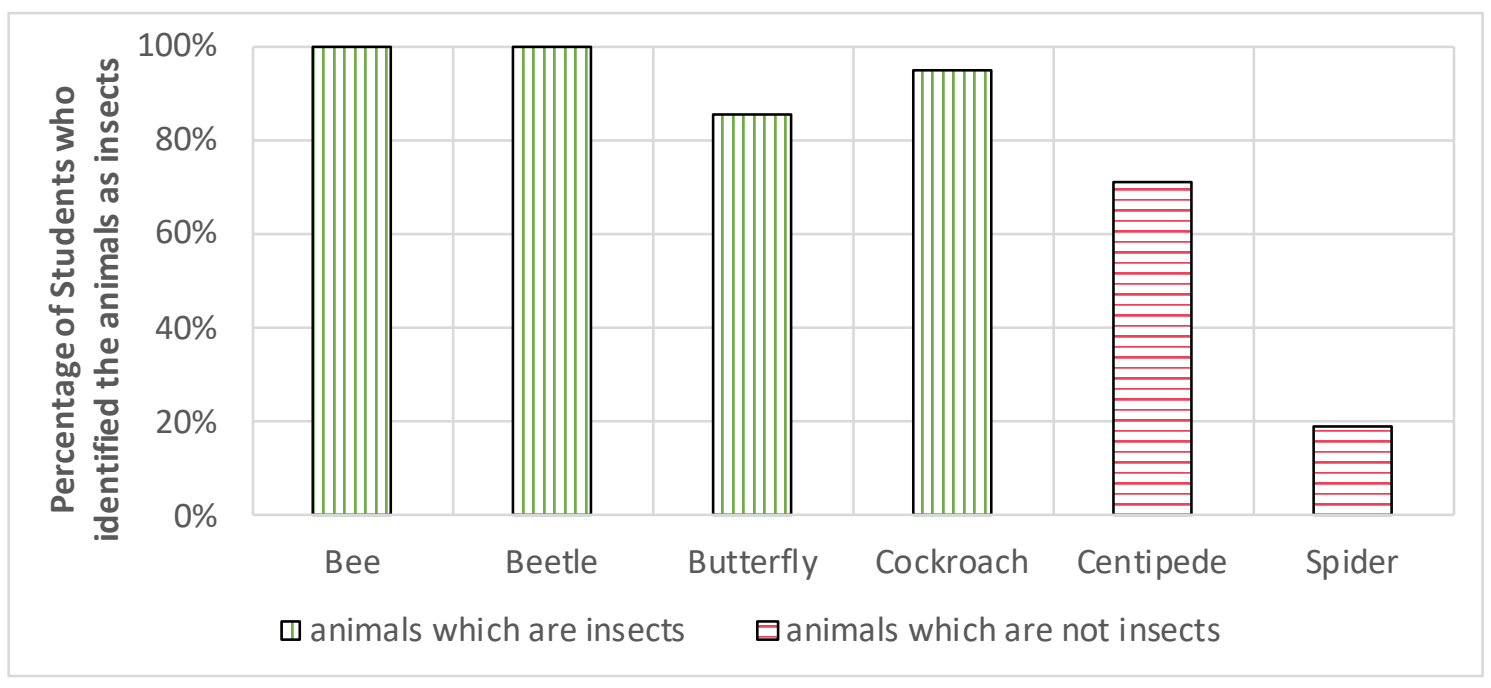

Figure 4. Animals identified as insects

Figure 5 shows a summary of the number of legs that were counted for each animal. Students indicated that spiders have ten or more than ten legs, while for cockroaches, it was indicated that they could have eight legs. A similar case occurs with bees, in which a student indicated that they have more than ten legs. Confusions occur mainly with the antennae of animals. It is interesting that for the students, it was easy to take the 3D models and observe each part in detail. When discussing these results with those obtained by the professor of the course in the original museum activity, he mentions that real animals are sometimes very small, which prevents them from having enough detail and generating this type of confusion.

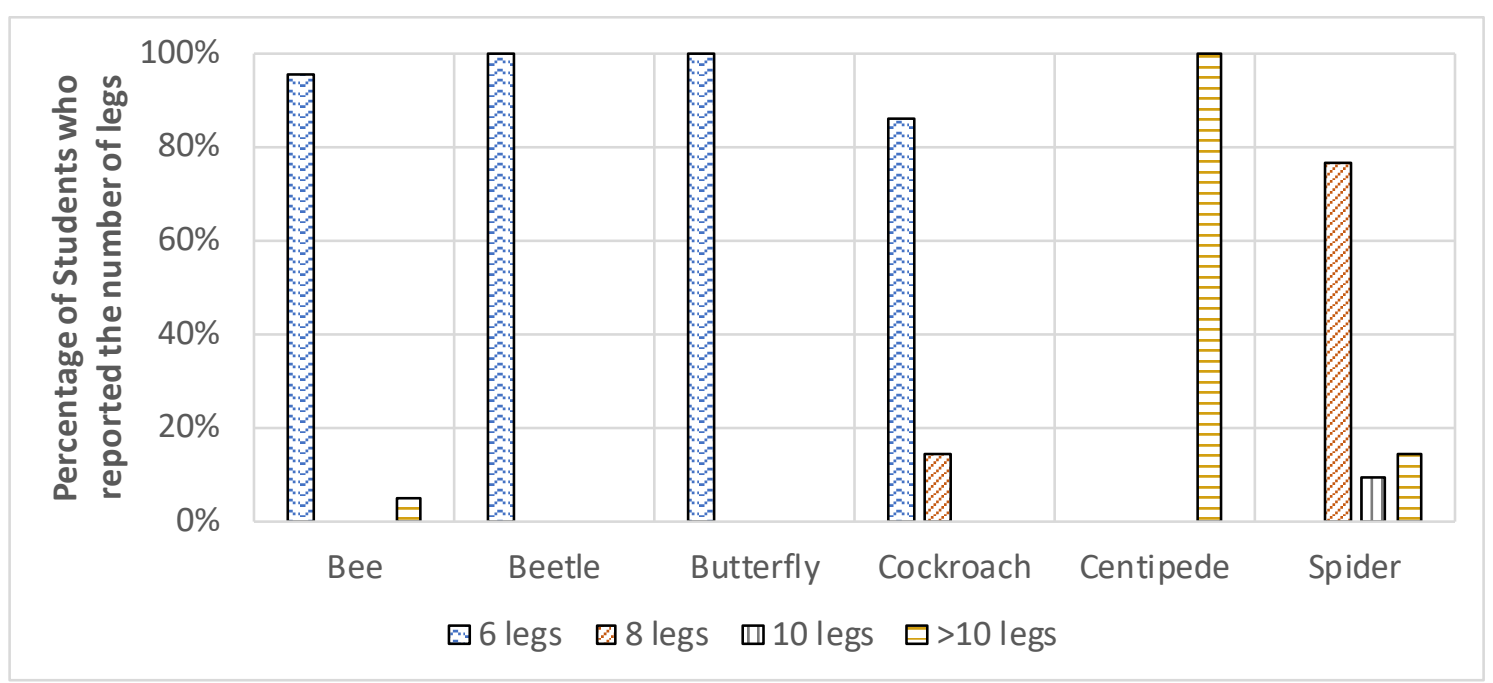

Figure 5. Identified/reported number of legs

Figure 6 shows the percentage of students who identified each arthropod as having wings. There were no complications in this part of the experience. Only one student did not notice the existence of wings in the cockroach. This can help improve the future experience, as it may be because the model used for the cockroach never opened its wings. 


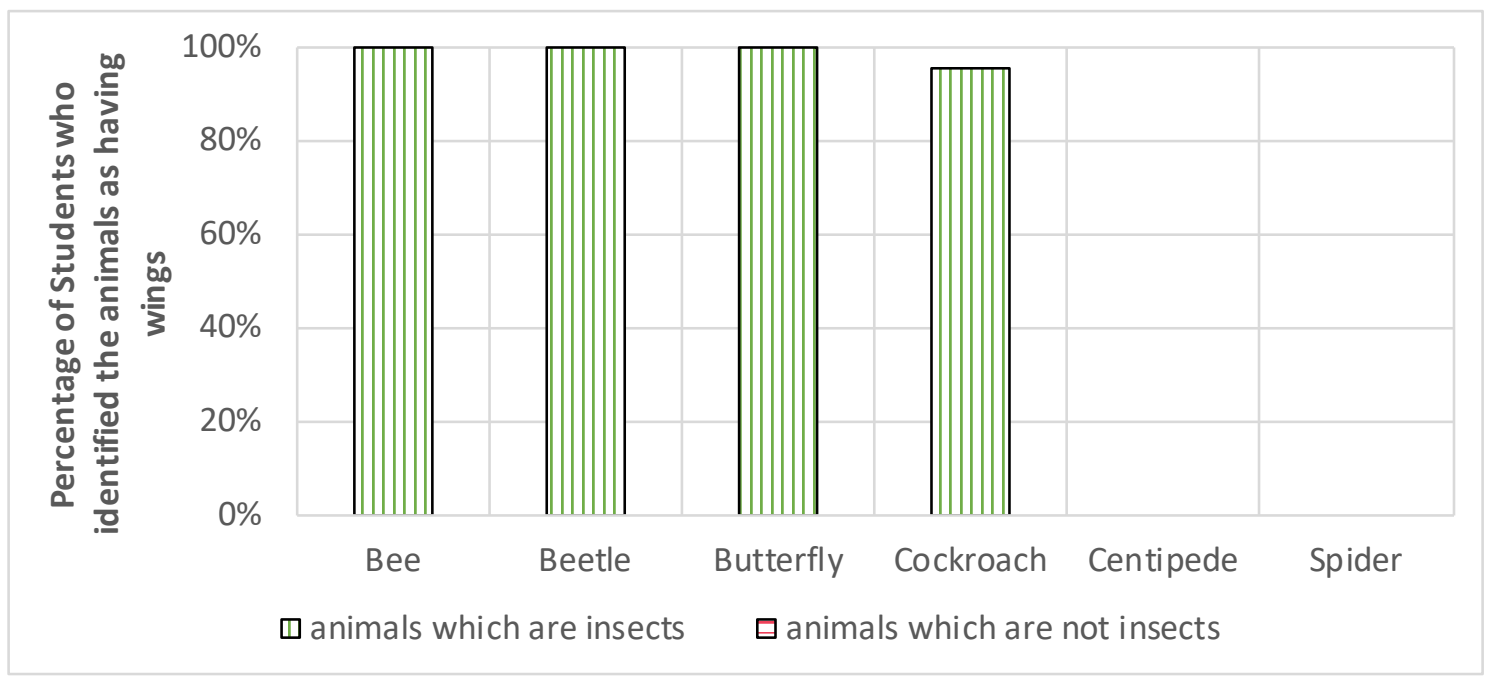

Figure 6. Animals identified as having wings

\section{Discussion}

This study's findings demonstrate that immersive virtual reality is a very helpful tool for learning about insects. During the experience, more than half the students infer the rule "An insect has wings and six legs" to distinguish an insect from other arthropods. This rule, although simple, is not common knowledge. It is important to note that the figure of the teacher continues to be important during learning. Specifically, this importance can be perceived in students who approached this rule but failed to establish it correctly. Some of these definitions were "The number of legs, and the ability to fly is a determining factor in the identification of an insect", and "Those with wings are insects". Cases like these represent about $20 \%$ of the students, so that including a teacher to guide the activity can generate a success of at least $80 \%$.

On the other hand, some students answered that spiders have ten legs because they count spider's palps as legs. The same thing happened with the cockroach; a student mistaken his anal encirclement for legs. This is an important result because we can see that the student's interaction with an insect model with a high level of detail generates new doubts for the student, and the teacher can help resolve them. These kinds of doubts hardly arise with other approaches such as watching a video or a slide presentation. Something interesting occurs with the centipede. Close to $70 \%$ of students classify it as an insect the first time, but from this group of students, $40 \%$ were able to infer the rule correctly, and near to $30 \%$ more establish that insects have wings, changing their first answer. So, the experience helps students understand what an insect is and can help correct their erroneous concepts.

As stated before, this VR experience is based on an activity developed in the course "Insectos $y$ Civilización". In the original activity a group of maximum 15 students may approach and observe the insects at the museum. The course's teacher mentions that a disadvantage is the size of the museum's room since it prevents all the students from getting close. The insects' size is also a problem, as it is not always possible to observe their details. The teacher also indicates that there is a great advantage in the virtual reality experience. The students can feel that they interact with the animals and not with a screen. He was surprised that doubts arose when counting the legs, especially with cockroaches, "this had not happened before and gave me tools to better explain the characteristics of these animals".

Additionally, the teacher mentions that fear is certainly a problem, "I have had cases of students who do not dare to enter the classroom". Although this study is not focused on treating fears or phobias, it was interesting to note that some students showed excessive fear of insects even in VR. It was possible to notice this fear since some of them cried out when they observed the animals; their hands sweated or expressed disgust. Specifically, six cases of this type were presented, all of them completed the activity even in the face of said fear; three of them managed to correctly infer the rule, and two others are included in the $20 \%$ of students that expressed a rule very close to the expected one. Some students joked about their own fears while doing the activity. For some, the fact of being immersed in what they felt was a video game allowed 
them to complete the activity. One of them expressed "It seems like a game, if I don't finish it, I feel like I lost".

It is important to note that the use of virtual reality generates a controlled space where students can learn while feeling safe against their own phobias or fears. Even feeling fear of the elements that surround them during the virtual experience, students can interact with these elements and assimilate knowledge. The collaboration is a functionality that can be exploited in future work since a teacher can connect to the environment and guide the student during the experience to make it more fruitful.

\section{Conclusions}

The test performed shows that eventually, a VR experience allows students to learn about insects. Although there was no mechanism to measure motivation, its increase was observed when using the virtual reality environment since all the students completed the test, even those afraid of the insects. It is interesting to discover other problems in these animals' knowledge, such as differentiating between legs and any other body parts. Although not all students managed to reach the rule to define what an insect is and what is not, they realized that the number of legs and the presence of wings are involved in this classification.

\section{Statement of conflict of interest}

The authors declared no potential conflicts of interest with respect to the research, authorship and/or publication of this article.

\section{Funding}

Victor Garzon's doctoral study program is supported by “Corporación de Incubación y fomento de empresas de base tecnológica - Cluster CreaTIC" with the project "Fortalecimiento de las capacidades de las EBT-TIC del Cauca para competir en un mercado global".

\section{Acknowledgments}

We thank to ConectaTE, the Uniandes' office technology in Education, for their support.

\section{ORCID iD}

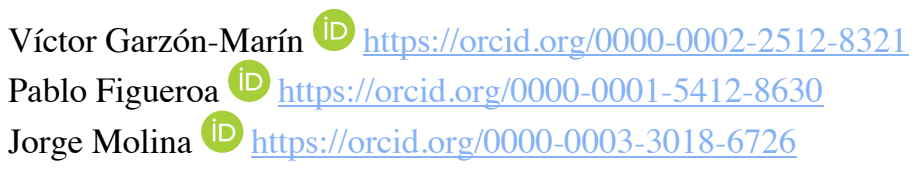

\section{Referencias}

Adefila, A., Opie, J., Ball, S., \& Bluteau, P. (2020). Students engagement and learning experiences using virtual patient simulation in a computer supported collaborative learning environment. Innovations in Education and Teaching International, 57(1), 50-61.

Afrooz, A., Ding, L., \& Pettit, C. (2019). An Immersive 3D Virtual Environment to Support Collaborative Learning and Teaching. In S. Geertman, Q. Zhan, A. Allan, \& C. Pettit (Eds.), International Conference on Computers in Urban Planning and Urban Management (pp. 267-282). Springer, Cham. https://doi.org/10.1007/978-3-030- 
19424-6 15

Ahir, K., Govani, K., Gajera, R., \& Shah, M. (2020). Application on Virtual Reality for Enhanced Education Learning, Military Training and Sports. Augmented Human Research, 5(1), 7. https://doi.org/10.1007/s41133-019-0025-2

Bethke, J. A., Kabashima, J. N., Newman, J. P., Robb, K. L., \& Wilen, C. A. (2014). Insect, Mites, and Other Invertebrate Pests. In Container Nursery Production and Business Management Manual, (pp. 201-223).

Campbell, J. W., Stanley-Stahr, C., Bammer, M., Daniels, J. C., \& Ellis, J. D. (2019). Contribution of bees and other pollinators to watermelon (Citrullus lanatus Thunb.) pollination. Journal of Apicultural Research, 58(4), 597603. https://doi.org/10.1080/00218839.2019.1614271

Carruth, D. W. (2017). Virtual reality for education and workforce training. 2017 15th International Conference on Emerging ELearning Technologies and Applications (ICETA), 1-6. https://doi.org/10.1109/ICETA.2017.8102472

Cho, Y. H., \& Lim, K. Y. T. (2017). Effectiveness of collaborative learning with 3D virtual worlds. British Journal of Educational Technology, 48(1), 202-211. https://doi.org/10.1111/bjet.12356

Fuller, C. (2020). Dermatoses Caused by Arthropods. In M. A., H. R., \& N. B. (Eds.), Skin Disorders in Migrants (pp. 55-57). Springer, Cham. https://doi.org/10.1007/978-3-030-37476-1_9

High Fidelity Inc. (2021). High Fidelity. https://www highfidelity.com/

Lin, E. C.-H., Shih, Y.-C., \& Chang, R.-C. (2018). A Research on Integrating AR and Multimedia Technology for Teaching and Learning System Design. In N. Yen \& J. Hung (Eds.), Frontier Computing (pp. 725-731). Springer, Singapore. https://doi.org/10.1007/978-981-10-3187-8_68

McCann, R. A., Armstrong, C. M., Skopp, N. A., Edwards-Stewart, A., Smolenski, D. J., June, J. D., MetzgerAbamukong, M., \& Reger, G. M. (2014). Virtual reality exposure therapy for the treatment of anxiety disorders: An evaluation of research quality. Journal of Anxiety Disorders, 28(6), 625-631. https://doi.org/10.1016/j.janxdis.2014.05.010

Miloff, A., Lindner, P., Dafgård, P., Deak, S., Garke, M., Hamilton, W., Heinsoo, J., Kristoffersson, G., Rafi, J., Sindemark, K., Sjölund, J., Zenger, M., Reuterskiöld, L., Andersson, G., \& Carlbring, P. (2019). Automated virtual reality exposure therapy for spider phobia vs. in-vivo one-session treatment: A randomized noninferiority trial. Behaviour Research and Therapy, 118, 130-140. https://doi.org/10.1016/j.brat.2019.04.004

Miss D., J. V., \& Cuauhtémoc, D. (2007). Observaciones sobre los coleópteros saproxilófilos (Insecta: Coleoptera) en Sotuta, Yucatán, México. In Revista Colombiana de Entomología (Vol. 33, Issue 1).

Nigam, A., Kabra, P., \& Doke, P. (2011). Augmented Reality in agriculture. 2011 IEEE 7th International Conference on Wireless and Mobile Computing, Networking and Communications (WiMob), 445-448. https://doi.org/10.1109/WiMOB.2011.6085361

Radianti, J., Majchrzak, T. A., Fromm, J., \& Wohlgenannt, I. (2020). A systematic review of immersive virtual reality applications for higher education: Design elements, lessons learned, and research agenda. Computers \& Education, 147, 103778. https://doi.org/10.1016/j.compedu.2019.103778

Southgate, E., Smith, S. P., Cividino, C., Saxby, S., Kilham, J., Eather, G., Scevak, J., Summerville, D., Buchanan, R., \& Bergin, C. (2019). Embedding immersive virtual reality in classrooms: Ethical, organisational and educational lessons in bridging research and practice. International Journal of Child-Computer Interaction, 19, 19-29. https://doi.org/10.1016/j.ijcci.2018.10.002

Tarng, W., Ou, K.-L., Yu, C.-S., Liou, F.-L., \& Liou, H.-H. (2015). Development of a virtual butterfly ecological system based on augmented reality and mobile learning technologies. Virtual Reality, 19(3-4), 253-266. https://doi.org/10.1007/s10055-015-0265-5 